\title{
Apresentação
}

\section{Cruzamentos interculturais: uma apresentação}

Ângela Maria Dias

Paula Glenadel

\section{"Primeiras palavras": tradição, tradução e criação na cultura contemporânea}

A concepção segundo a qual toda escrita ou invenção é uma forma de releitura de obras já existentes, que certamente não deixa de ser congenial à constituição das séries artísticas do ocidente, embora se encontre mais assiduamente teorizada desde a vigência da literatura crítica da modernidade, consiste agora no processo-chave da criação de novas linguagens. Ela é visível não apenas na importância concedida à leitura e à resposta dos leitores, mas também na hibridização entre gêneros e práticas discursivas, com fronteiras cada vez mais indistintas, num espelhamento entre modalidades ficcionais, autobiográficas, históricas e ensaísticas.

De certa maneira, a miscigenação de registros e formas artísticas, em cruzamentos de efeitos inusitados, ampliada desde a invenção do cinema, no início do século vinte, vem-se radicalizando contemporaneamente pela centralidade do computador, onde circulam vorazmente, numa disposição não hierárquica, textos, filmes, músicas, fotografias, pinturas e nos hipertextos, montagens de variada fatura, onde múltiplas interseções de linguagens se perfazem. Esta permeabilidade entre códigos e suportes, bastante difundida pelo processo da adaptação cinematográfica de romances, hoje se acentua pelo fluxo de metamorfoses constantes entre meios e suportes, quando uma mesma narrativa, ficcional ou não, pode ser veiculada de diferentes maneiras: como texto, ou vídeo, ou cinema, ou animação, ou entrevista, ou ainda como reportagem de televisão.

Esta estética de migrações e transposições, entendida como modo de produção artístico-cultural contemporâneo decorrente do protagonismo da tecnologia, banaliza, de certa maneira, o intercâmbio e a integração de códigos e linguagens propostos pelas vanguardas, no início do século XX, e tende a entronizar uma dinâmica criativa altamente fundada no jogo intertextual da citação, da paródia, da tradução como constantes.

Haroldo de Campos, em sua prolífica obra de crítico-tradutor, reiteradamente considera a Literatura como fazer e sua História, como um sistema não linear de produção de intertextos, 
em que "a plagiotropia (...) se resolve em tradução da tradição, num sentido não necessariamente retilíneo" (CAMPOS, 1997, p. 48). Ao conectar tal jogo de citações com a paródia, o escritor lembra o "seu sentido etimológico de 'canto paralelo"', abrangendo nela tanto o "diálogo de textos" ou "intertextualidade" (na fórmula de Kristeva, derivada de Bakhtin), como a noção estrita (em Tinianov, por exemplo) de paródia como "inversão (cômica) do texto parodiado" (CAMPOS, 1997, p. 56)

Nesse sentido, a ativação do acervo tradicional promovida pela tradução, ao constituir "uma operação de crítica ao vivo", vai ser concebida pelo crítico como "transcriação", distanciando-se da "tradução referencial, do significado" por proceder a "uma operação sobre a materialidade do significante" (CAMPOS, 1997, p. 46). Essa disposição dialógica inerente à vocação paródica da tradução é, ademais, vista por Haroldo de Campos como inerente ao próprio ato de escrever. Assim, ao debruçar-se sobre a tradução do Segundo Fausto de Goethe, o teórico interpreta a obra como um momento irônico de uma longa tradição de releituras, desde o primeiro Fausto de 1587, "uma singular epopéia dialógica" que carnavaliza o Paraíso de Dante (CAMPOS, 1997, p. 59).

Mas a recodificação promovida pelo agenciamento tradutor deve ser de natureza poética capaz de reinventar a iconicidade do signo estético, no texto original, sua fisicalidade, o som, o movimento, a forma. Daí a convergência de tal concepção com a visão de Benjamin, no seu ensaio "A tarefa do tradutor", sobre a oxigenação da língua tradutora sob o influxo da "língua pura" haurida do original, e entendida por Campos "em termos de um código intra-e-inter-semiótico, latente na poesia de todas as línguas, e exportável de uma a outra, como um sistema geral de formas significantes" (CAMPOS, 1997, p. 56). Semelhantemente, a visão derridiana de tradução, contemplando a "multiplicidade de línguas e a impureza do limite" (DERRIDA, 1999, p. 23) acaba revelando-se como equivalente a uma poética, por colocar como indecidida a questão de uma escolha simples entre linguagem e metalinguagem, bem como entre uma língua e outra.

No seu empenho em vincular as duas línguas e estabelecer pontes entre elas, o tradutor elege a aventura da busca pela alteridade, movido pelo sentimento da diferença que modelou a torre de Babel como o fundamento da linguagem, na plasmação das linguagens. E nesse sentido, ele assume, no nosso "mundo de línguas em contato", "o ethos comparatista - a razão dialógica, o respeito à diferença e o reconhecimento da diversidade - em contraposição à hegemonia, à homogeneização e ao monolinguismo" (SCHMIDT, 2010, p. 10).

Assim, na atualidade imantada pela centralidade do aparato tecnológico-informacional, o principal viés-teórico metodológico da literatura comparada, como privilegiada estratégia de conhecimento e compreensão das diferenças identitárias

Niterói, n. 31, p. 5-11, 2. sem. 2011 
no mundo globalizado, consiste na tradução. Os eixos do comparatismo - "a intertextualidade, a interdiscursividade e a interdisciplinaridade" (SCHMIDT, 2010, p. 11) - constituem os instrumentos da prática tradutória e as marcas do seu compromisso com a reconstituição dos diálogos culturais, na construção de uma historiografia francamente transcultural, fundada na ultrapassagem das limitações do conceito de literatura nacional.

A compreensão da série literária - hoje profundamente hibridizada com outros códigos e suportes artísticos e informacionais - se balizada por um relacionismo não linear e polifônico, "em que cada novo texto funcionaria como interpretante do fundo textual anterior" (CAMPOS, 1997, p. 56), constituirá o melhor instrumento para o estudo da heterogeneidade histórico-cultural implicada na noção de comunidades interliterárias e interculturais.

Em plena vigência da mundialização econômico-cultural, o impacto das incessantes transformações tecnológicas em diferentes contextos político-sociais faz da questão identitária, numa perspectiva anti-isolacionista, o núcleo crucial de indagações, frente a fenômenos simultâneos e conjugados, tais como o conflito de etnias, a emergência de novos nacionalismos, a importância estratégica das alianças regionais, o surgimento movimentos sociais de contestação forjados pela internet.

O próprio conceito de literatura nacional, hoje atravessado pelo eco de vozes não hegemônicas e descontinuidades, mostra-se inteiramente incompatibilizado com os parâmetros restritos ao lugar de produção, característicos dos nacionalismos tradicionais, já que, além das alteridades internas, há nações não tão claramente separadas ou distintas por fronteiras geopolíticas, lingüísticas e culturais, além daquelas propriamente sem estado, como, por exemplo, as dos curdos, bascos e palestinos (SCHMIDT, 2010, p. 154).

Por outro lado, numa confirmação do teor altamente complexo inerente à fisionomia cultural da contemporaneidade, "a nação continuaria funcionando globalmente como um componente irredutível da identidade, muito embora (...) esse termo (seja) incapaz de registrar as diferenças múltiplas e incomensuráveis que dividem uma nação de si própria e das outras" (SCHMIDT, 2010, p. 155).

Por isso mesmo, a tradução constitui a pedra de toque do trabalho comparatista, num universo inundado de interseções e cruzamentos culturais, tanto a nível econômico e geopolítico, quanto em termos comunicacionais e artísticos. A tradução cultural, como operação indispensável para redução das dessimetrias entre poderes lingüísticos e culturais hegemônicos e línguas minoritárias, sem dúvida, está no centro do trabalho comparatista para promover trânsitos e remover fronteiras. 
Spivak, em "Rethinking Comparativism", de 2009, crê numa espécie de equivalência entre as línguas, fundada em "circuitos metapsicológicos de uma memória lingual" (SPIVAK, 2009, p. 612) e propõe que esta equivalência deva ser ativada pelo comparatismo, num esforço para produzir um simulacro, através da reflexividade da linguagem, capaz de traduzir, não o conteúdo, mas os movimentos "linguageiros"("but the very moves of languaging").

Talvez possamos aproximar tal afirmação da hipótese benjaminiana sobre o horizonte de uma "língua pura" como fundamento da afinidade entre as línguas passível de emergir, pelo amoroso esforço da tradução em conceber na outra língua "o modo de intencionar do original" (BENJAMIN apud CAMPOS, 1997, p. 54).

A tradução baseada na equivalência, porque pautada por uma profunda aprendizagem de línguas voltada para a "implosão de um simulacro da memória lingual", poderia, segundo a autora indiana, contrapor-se aos jogos de poder implicados na desigualdade entre línguas hegemônicas e subalternas, e ser capaz de inaugurar um tipo de contato com o idioma estrangeiro, bastante diferente do "de um comparatista que supostamente ocupa um lugar acima das tradições lingüísticas a serem comparadas" (SPIVAK, 2009, p .613).

O lugar do comparatista como tradutor transcultural, neste mundo de culturas entrelaçadas, tem a ver com o que Edward Said desenvolve, em suas conferências Reith, de 1993, sobre as "representações do intelectual". Na atualidade abarrotada de especialistas, do alto de sua autoridade e das recompensas que auferem, o intelectual, fiel ao papel público, característico de sua vocação para representar - isto é, "dar corpo e articular uma mensagem" (SAID, 2005, p. 25) reconhecida publicamente-deve buscar esquivar-se aos "estereótipos e às categorias redutoras que tanto limitam o pensamento humano e a comunicação" (SAID, 2005, p. 10). Nesse sentido, o permanente questionamento de gregarismos como o "nacionalismo patriótico, o pensamento corporativo e um sentido de privilégio de classe, raça ou sexo" (SAID, 2005, p. 13) constitui o permanente desafio de um sujeito comprometido com a liberdade humana e o conhecimento.

Mais adiante, ao falar sobre Adorno, como "o intelectual por excelência" (SAID, 2005, p. 63), Said recupera o que considera, na obra do pensador da Escola de Frankfurt, "a essência da representação do intelectual como um exilado permanente" (SAID, 2005, p. 64). A "perspectiva dupla ou de exílio" como "posto de observação do exilado para o intelectual" (SAID, 2005, p. 68) significa exercer o "desassossego", o movimento constante, o deslocamento, a partir dos quais "uma ideia ou experiência é sempre contraposta a outra, fazendo com que ambas apareçam sob uma luz às vezes nova e imprevisível" (SAID, 2005, p. 67). 
Possivelmente, esta mesma perspectiva caracteriza a preocupação de Spivak com o comparativismo como um gesto político (SPIVAK, 2009, p. 616) na ultrapassagem da "injustiça histórica diante de línguas associadas com povos não competitivos dentro do modo de produção capitalista", buscando estabelecer entre elas uma interconexão, na criação de uma coletividade subalterna de línguas fora das fronteiras da cultura das Nações Unidas. (SPIVAK, 2009, p. 613, 614)

A perspectiva utópica da proposta de uma leitura das margens agenciada pelas línguas mais prestigiadas econômica e culturalmente, por meio de cuidadosa escuta, constitui um horizonte de expectativas capaz de revestir eticamente a tradução e o comparatismo que pressupõe, impedindo que se tornem reféns das malhas dos nacionalismos estreitos e ou da instrumentalização do outro. A estratégia do exílio como lugar do intelectual, ao obrigá-lo sempre a descentrar-se de sua própria casa, certamente, pode construir um profícuo "entre-lugar" em que as coisas nunca sejam vistas de maneira isolada; propiciando um enfoque transcultural, no qual, "uma ideia ou experiência seja sempre contraposta a outra, fazendo com que ambas apareçam sob uma luz às vezes nova e imprevisível" (SAID, 2005, p.67).

Nesse sentido, em seu texto simultaneamente filosófico e autobiográfico sobre o monolinguismo do outro, que é também o seu, Derrida ressalta a importância dentro da própria cultura greco-latina-cristã do ocidente de certos pontos de passagem, ou de tradução, em que ela se comunica com um ailleurs, um fora, que permanece aberto, e demanda tradução: "khôra, a teologia negativa, mestre Eckhart e além, Freud e além, um certo Heidegger, Artaud, Lévinas, Blanchot, e alguns outros" (DERRIDA, 1996, p. 132). Este "fora" nos fala de uma outra racionalidade, de uma outra relação com a língua e com o outro, que teriam uma potência de estremecimento da geografia do centro e das margens, onde a tradução apareceria como contínuo deslocamento entre essas posições. Nesta encruzilhada difícil e melancólica, pois incerta e exigente, onde "Nada é intraduzível num sentido, mas em outro sentido tudo é intraduzível, a tradução é um outro nome do impossível" (DERRIDA, 1996, p. 103)", talvez se possa vislumbrar a possibilidade de um inusitado e fortuito universalismo.

\section{O tema nas perspectivas dos artigos}

Os artigos que integram este número responderam à chamada para refletir sobre o tema de maneiras muito diferentes, comprovando a complexidade e a pertinência da reflexão sobre os cruzamentos interculturais em nossos dias. Em que pese a diversidade das abordagens apresentadas, é possível perceber que os artigos se distribuem em três grandes eixos - que, contudo, não se organizam de maneira linear no sumário. Entre 
esses eixos de reflexão teórica, há todo um jogo de tons e temas, que presidiram à organização sequencial dos textos na revista.

O primeiro eixo agrupa textos mais explicitamente vinculados à tradução, que trazem como contribuição o aprofundamento da compreensão de como o desenvolvimento de ferramentas de tradução afeta o envolvimento do tradutor com seu trabalho (Érika Nogueira de Andrade Stupiello), bem como dos valores que a tradução pode assumir num contexto de confronto com outras atividades ligadas à linguagem, como o jornalismo (Meta Elisabeth Zipser e Michelle de Abreu Aio), e com o contexto do mercado editorial, da mídia ou da academia (Maria Clara Castellões de Oliveira).

O segundo eixo é marcado por uma reflexão sobre o luto e a ética, em textos que buscam dotar os processos presentes na tradução de um valor teórico, seja integrando aspectos diversos da atividade do intelectual pós-colonial, marcados pela perda daqueles privilégios que o tradutor deteria com relação ao subalterno, que se transforma em solidariedade e hospitalidade (Sandra Regina Goulart Almeida), seja detectando uma certa melancolia da desconstrução como a (im)possível tradução da metafísica ocidental, da linguagem que nos constitui (Jacob Rogozinski); ou, ainda, sublinhando a importância de "traduzir", refinando-as, nossas representações da morte como mera destruição para enxergá-la como motor de uma estética, notadamente na literatura brasileira (Jaime Ginzburg). Encontram-se aqui, ainda, a produtividade das noções de herança, tributo e homenagem na lírica moderna e contemporânea, marcadas por uma "política da amizade" que muitas vezes se desdobra em trabalho de luto (Antonio Andrade), a caracterização do "desterro" do poeta como fonte da dimensão solidária e ética de sua escrita (Margareth dos Santos) e o luto de uma mitologia da pureza linguística abrindo-se à criatividade no conflito entre as lógicas ocidental e crioula que gera debates sobre o uso da língua francesa por escritores francófonos (Arnaldo Rosa Vianna Neto). Numa perspectiva marcada pelo desencanto com o contemporâneo, porém combativa e interventiva, o texto de Michel Deguy procura fazer dialogar arte e justiça, julgamento estético e ético, lendo o filme de Lumet.

No terceiro eixo, há os textos que encenam cruzamentos entre a literatura e as outras artes, refletindo sobre a carnavalização e a paródia na obra de Zappa (Vanderlei José Zacchi), a pintura no teatro de Beckett (Sônia Maria Materno de Carvalho), a música e a produção de subjetividades (Pedro Dolabela Chagas). Também fazem parte desse conjunto os textos que investigam fronteiras, como a que separa o homem dos animais (Milla Benício Ribeiro de Almeida), as representações literárias do masculino e do feminino (Maria Conceição Monteiro), o interior e o exterior de 
um texto de ficção (André Rangel Rios), ou a transposição daquilo que era dado ontológico do humano em dado neurológico, numa atual cultura somática (Maria Cristina Franco Ferraz). Alguns textos abordam a intertextualidade, vendo a reescrita como parte fundamental dos processos de criação intertextual para a literatura portuguesa contemporânea (José Cândido de Oliveira Martins), ou explicitando as relações entre a produção ficcional de Blanchot, relativamente pouco explorada entre nós, e a literatura de Kafka (Davi Andrade Pimentel). Merece especial atenção, pelo lugar anfíbio em que se move o seu autor, o texto em que se trata das relações indecidíveis entre o que é vida e o que é letra no universo de um escritor de autoficção (Silviano Santiago).

Completando o conjunto de artigos da revista, há duas resenhas, uma das quais discute aspectos da tradução uruguaia das Galáxias de Haroldo de Campos (Rosario Lázaro Igoa), e a outra comenta a proposta de abordagem do abjeto na literatura e nas artes em coletânea recentemente publicada pela EdUFF (Renan Ji).

\section{REFERÊNCIAS}

CAMPOS, Haroldo de. O arco-íris branco. Ensaios de Literatura e Cultura. Rio de Janeiro: Imago, 1997.

DERRIDA, Jacques. Le monolinguisme de l'autre. Paris: Galilée, 1996.

. Qu'est-ce qu'une traduction "relevante"? Actes des quinzièmes assises de la traduction littéraire (1998, Arles). Arles : Actes Sud, 1999.

SAID, Edward. Representações do intelectual As Conferências de Reith de 1993. Trad. Milton Hatoum. São Paulo: Companhia das Letras, 2005.

SCHMIDT, Rita Terezinha. Apresentação. In: ___ (org.). Sob o signo do presente - intervenções comparatistas. Porto Alegre: Ed. da UFRGS, 2010, p. 9-13.

Repensando o lugar do nacional no comparatismo. In: (org.). Sob o signo do presente - intervenções comparatistas.

Porto Alegre: Ed. da UFRGS, 2010, p.149-166.

SPIVAK, Gayatri Chakravorty. Rethinking Comparativism. In: New Literary History n. 40, v. 3, p. 609-626, 2009. 